\title{
Effect of ear-defenders (ear-muffs) on the localization of sound
}

\author{
G. R. C. ATHERLEY and W. G. NOBLE \\ Department of Pure and Applied Physics, University of Salford and Department of \\ Occupational Health, University of Manchester
}

\begin{abstract}
Atherley, G. R. C., and Noble, W. G. (1970). Brit. J. industr. Med., 27, 260-265. Effect of ear-defenders (ear-muffs) on the localization of sound. In a laboratory study we examined the influence of ear-defenders (ear-muffs), of a type used in industry, on a localization task using the binaural (diotic) presentation of a $1 \mathrm{KHz}$ pure tone under anechoic conditions. Our subjects were 15 foundry workers, none of whom had ever used hearing protection. Fourteen men made more errors of localization with the ear-defenders than without; the other man scored equally in both conditions. For the group as a whole the total number of possible responses in one or the other condition was 720; the total correct score with defenders was 360 and the equivalent score without defenders was 546. All subjects except one showed an increase in left/right errors with the defenders. Without ear-defenders the group as a whole made 13 left/right errors; with them the number rose to 113 . When they were unsure, subjects tended to make rearward in preference to frontward judgements. We concluded that our findings, especially in regard to left/right errors, may be of importance from the point of view of the safety of workpeople in industry.
\end{abstract}

Men in foundries have reported to us that eardefenders (ear-muffs) reduce the ability to tell the direction of sound. We were not able to judge whether this complaint had any real basis because there appeared to be no existing knowledge of such an effect.

We decided, therefore, to examine in detail the influence of ear-defenders, of a type used in industry, on directional hearing. Although the tests were made in a laboratory, the subjects were men who worked in the foundry industry; they had no previous experience of hearing protection.

\section{Experimental apparatus and method}

The various methods for investigating auditory direction perception have been discussed by Howard and Templeton (1966). A binaural (diotic) presentation was chosen in a localization task under anechoic conditions; open ears were compared with ears closed by ear-defenders.

In an anechoic chamber the subject was seated on a stool and was surrounded by six loudspeakers, at head height, $60^{\circ}$ apart and 52 in $(1.32 \mathrm{~m})$ from him.

The stimulus used was a pure tone of $1 \mathrm{KHz}$. This frequency was chosen because: (1) Jongkees and van der Veer (1957) have shown that the degree of loss in directional hearing ability at this frequency bears no relation to inter-aural differences in auditory acuity, and (2) in terms of minimum audible angle, auditory localization ability is consistent up to frequencies slightly higher than $1 \mathrm{KHz}$, but beyond this there is greater variation with frequency (Mills, 1958).

The stimulus was generated by a Peters SPD 5 audiometer. The signal from the audiometer was taken through an amplifier and on to a selector switch which allowed the signal to be directed to any one of the six loudspeakers. Stevens and Newman (1936) pointed out the effectiveness of clicks, such as switching transients, as cues to the perception of direction. The use of an audiometer and a suitably designed selector switch ensured that the system was entirely free from clicks in all of its operations. A $10 \mathrm{~dB}$ attenuator in the output circuit of the amplifier made its hum inaudible. 
The six loudspeakers were balanced by means of individual pre-set attenuators so that the sound pressure level of a $1 \mathrm{KHz}$ tone, measured at the centre of the circle, did not differ between the loudspeakers by more than $1 \mathrm{~dB}$.

The advantage to be gained by movements of the head in attempts to perceive the direction of a signal was shown by Wallach (1940) and again by Fisher and Freedman (1968) In the experiments of Fisher and Freedman the subject's head was physically restrained to control this factor. In our study, as the subjects were men from industry, the idea of physical restraint was rejected because, in the unfamiliar environment of an anechoic chamber, they might have found this intolerable. Each subject was told not to move his head when he heard a signal.

\section{Subjects and procedure}

There were 15 men in the experiment, all of whom worked in some part of the foundry industry. None of them had ever used hearing protection. To aid the subject, a chart was drawn showing the positions of the six loudspeakers labelled 1 to 6 for his reference (Figure). This chart was placed exactly midway between two loudspeakers, facing the subject and beyond the implied circumference of the circle. The subject was asked to state, through an intercommunication system, the number of the loudspeaker from which he judged a test-tone to have come. Although all test-tones were audible to the subject, there were occasions when he was unable to decide on a number. Such a response was recorded as zero.

In the trial runs, it was noticed that the ability to locate the direction of a $1 \mathrm{KHz}$ tone was diminished at low sensation levels. To explore this finding the stimuli were presented at four different sensation levels $(10,20,30$, and $40 \mathrm{~dB}$ ) in both open and occluded ear conditions. To ensure that each stimulus was heard in both series, the subject first judged which of the six loudspeakers was the quietest. His threshold level at $1 \mathrm{KHz}$ was then estimated for that loudspeaker by the method of limits and the sensation level was calculated always from that threshold.

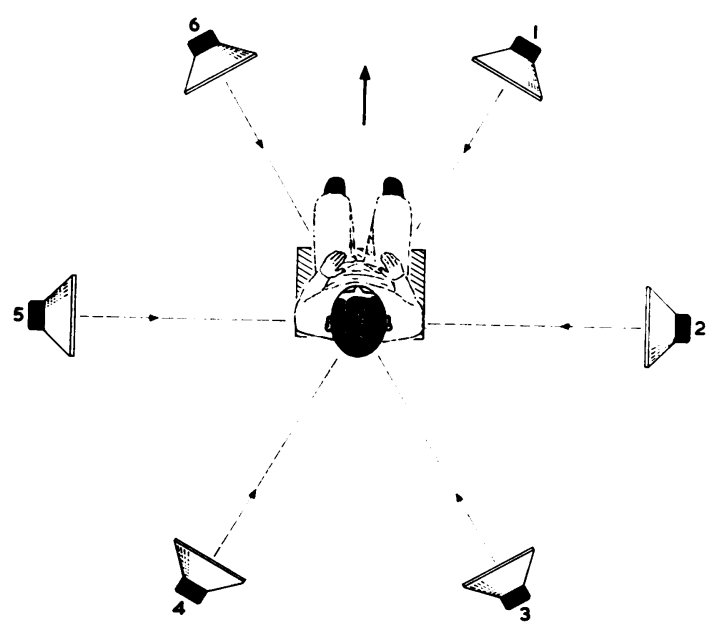

FIGURE Chart showing positions of six loudspeakers.
The absolute level of threshold and the absolute magnitude of the signal are excluded as factors because sensation level was used. However, the question of loss of hearing acuity was still a possible factor of importance; it is discussed later. The attenuation of the eardefenders was about $35 \mathrm{~dB}$ at $1 \mathrm{KHz}$ and it was not possible, with some subjects, to generate an undistorted signal at $40 \mathrm{~dB}$ sensation level. In those cases the sensation levels were altered to $10,20,25$, and $30 \mathrm{~dB}$.

Starting with the ears unoccluded and at the highest sensation level, two test-tones were presented in each of the six loudspeakers, in random order. The results from this trial were discarded and the procedure was repeated with the presentations in a different, but again random, order. A further three trials were then made at the remaining sensation levels, 10,30 , and $20 \mathrm{~dB}$, in that order.

The purpose of our disregarding the first trial was to overcome the effect of practice, which is known to be of importance in similar experiments (Fisher and Freedman, 1968).

After a short rest the subject was given the ear-defenders and five trials were made as before. Again the first trial was at the highest sensation level and the results from it were discarded.

\section{Results}

For the purpose of the analysis the physical locations of the stimuli are labelled $A$ to $F$ and subjective locations are labelled I to VI. Thus the correct responses are A I, B II, C III, D IV, E V, and F VI respectively; any other combinations of characters are incorrect responses.

Table 1 shows the number of correct responses at each of the six loudspeaker positions for each of the 15 subjects in the unoccluded (ND) and occluded (D) conditions. The total correct score is shown for each subject, and from these figures it can be seen that 14 subjects had fewer correct responses when they were wearing the ear-defenders. The remaining man had the same score in both conditions. For the group as a whole the total number of possible responses in one or other of the conditions was 720; the total correct D score was 360 and the equivalent ND total was 546.

The results have been analysed separately for the six loudspeaker positions. The correct D and ND scores were paired for each subject and the differences were tested using the Wilcoxon matched-pairs signed-ranks test. The levels of significance are shown in Table 1; at only one of the six loudspeaker positions are the differences in scores not significant (level of significance for a one-tailed test, 0.025).

The system of recording the responses was such that information about the incorrect responses was available and there follows an analysis of the patterns into which these errors fell.

Analysis of error

Ipsilateral and contralateral responses An ipsilateral 
TABLE 1

Correct Responses by the 15 Subjects for Six Loudspeaker Positions

\begin{tabular}{|c|c|c|c|c|c|c|c|c|}
\hline \multicolumn{2}{|c|}{ Subject } & $A I$ & B II & C III & $D I V$ & $E V$ & $F V I$ & $\begin{array}{c}\text { Total } \\
\text { correct scores }\end{array}$ \\
\hline 1 & $\begin{array}{r}\text { D } \\
\text { ND }\end{array}$ & $\begin{array}{l}7 \\
8\end{array}$ & $\begin{array}{l}7 \\
8\end{array}$ & $\begin{array}{l}7 \\
8\end{array}$ & $\begin{array}{l}6 \\
8\end{array}$ & $\begin{array}{l}0 \\
8\end{array}$ & $\begin{array}{l}6 \\
8\end{array}$ & $\begin{array}{l}33 \\
48\end{array}$ \\
\hline 2 & $\begin{array}{r}D \\
\text { ND }\end{array}$ & $\begin{array}{l}5 \\
7\end{array}$ & $\begin{array}{l}5 \\
8\end{array}$ & $\begin{array}{l}5 \\
8\end{array}$ & $\begin{array}{l}6 \\
8\end{array}$ & $\begin{array}{l}4 \\
0\end{array}$ & $\begin{array}{l}3 \\
8\end{array}$ & $\begin{array}{l}28 \\
39\end{array}$ \\
\hline 3 & $\begin{array}{r}\text { D } \\
\text { ND }\end{array}$ & $\begin{array}{l}7 \\
8\end{array}$ & $\begin{array}{l}6 \\
8\end{array}$ & $\begin{array}{l}4 \\
7\end{array}$ & $\begin{array}{l}5 \\
7\end{array}$ & $\begin{array}{l}4 \\
6\end{array}$ & $\begin{array}{l}8 \\
6\end{array}$ & $\begin{array}{l}34 \\
42\end{array}$ \\
\hline 4 & $\begin{array}{r}\text { D } \\
\text { ND }\end{array}$ & $\begin{array}{l}0 \\
0\end{array}$ & $\begin{array}{l}2 \\
3\end{array}$ & $\begin{array}{l}7 \\
8\end{array}$ & $\begin{array}{l}4 \\
2\end{array}$ & $\begin{array}{l}1 \\
6\end{array}$ & $\begin{array}{l}0 \\
2\end{array}$ & $\begin{array}{l}14 \\
21\end{array}$ \\
\hline 5 & $\begin{array}{r}D \\
\text { ND }\end{array}$ & $\begin{array}{l}7 \\
8\end{array}$ & $\begin{array}{l}6 \\
8\end{array}$ & $\begin{array}{l}3 \\
8\end{array}$ & $\begin{array}{l}7 \\
8\end{array}$ & $\begin{array}{l}8 \\
8\end{array}$ & $\begin{array}{l}1 \\
8\end{array}$ & $\begin{array}{l}32 \\
48\end{array}$ \\
\hline 6 & $\begin{array}{r}\text { D } \\
\text { ND }\end{array}$ & $\begin{array}{l}0 \\
8\end{array}$ & $\begin{array}{l}2 \\
7\end{array}$ & $\begin{array}{l}1 \\
4\end{array}$ & $\begin{array}{l}4 \\
7\end{array}$ & $\begin{array}{l}2 \\
6\end{array}$ & $\begin{array}{l}1 \\
2\end{array}$ & $\begin{array}{l}10 \\
34\end{array}$ \\
\hline 7 & $\begin{array}{r}\text { D } \\
\text { ND }\end{array}$ & $\begin{array}{l}4 \\
5\end{array}$ & $\begin{array}{l}0 \\
5\end{array}$ & $\begin{array}{l}5 \\
3\end{array}$ & $\begin{array}{l}7 \\
6\end{array}$ & $\begin{array}{l}2 \\
8\end{array}$ & $\begin{array}{l}2 \\
7\end{array}$ & $\begin{array}{l}20 \\
34\end{array}$ \\
\hline 8 & $\begin{array}{r}D \\
\text { ND }\end{array}$ & $\begin{array}{l}\mathbf{0} \\
\mathbf{0}\end{array}$ & $\begin{array}{l}3 \\
1\end{array}$ & $\begin{array}{l}6 \\
5\end{array}$ & $\begin{array}{l}3 \\
7\end{array}$ & $\begin{array}{l}6 \\
7\end{array}$ & $\begin{array}{l}3 \\
2\end{array}$ & $\begin{array}{l}21 \\
22\end{array}$ \\
\hline 9 & $\begin{array}{r}\text { D } \\
\text { ND }\end{array}$ & $\begin{array}{l}3 \\
5\end{array}$ & $\begin{array}{l}1 \\
8\end{array}$ & $\begin{array}{l}3 \\
3\end{array}$ & $\begin{array}{l}6 \\
6\end{array}$ & $\begin{array}{l}8 \\
8\end{array}$ & $\begin{array}{l}0 \\
2\end{array}$ & $\begin{array}{l}21 \\
32\end{array}$ \\
\hline 10 & $\begin{array}{r}\text { D } \\
\text { ND }\end{array}$ & $\begin{array}{l}5 \\
8\end{array}$ & $\begin{array}{l}4 \\
7\end{array}$ & $\begin{array}{l}7 \\
8\end{array}$ & $\begin{array}{l}6 \\
8\end{array}$ & $\begin{array}{l}5 \\
8\end{array}$ & $\begin{array}{l}7 \\
6\end{array}$ & $\begin{array}{l}34 \\
45\end{array}$ \\
\hline 11 & $\begin{array}{r}\text { D } \\
\text { ND }\end{array}$ & $\begin{array}{l}7 \\
8\end{array}$ & $\begin{array}{l}8 \\
8\end{array}$ & $\begin{array}{l}5 \\
7\end{array}$ & $\begin{array}{l}8 \\
8\end{array}$ & $\begin{array}{l}3 \\
8\end{array}$ & $\begin{array}{l}8 \\
8\end{array}$ & $\begin{array}{l}39 \\
47\end{array}$ \\
\hline 12 & $\begin{array}{r}\text { D } \\
\text { ND }\end{array}$ & $\begin{array}{l}8 \\
8\end{array}$ & $\begin{array}{l}7 \\
0\end{array}$ & $\begin{array}{l}4 \\
7\end{array}$ & $\begin{array}{l}6 \\
5\end{array}$ & $\begin{array}{l}2 \\
7\end{array}$ & $\begin{array}{l}8 \\
8\end{array}$ & $\begin{array}{l}35 \\
35\end{array}$ \\
\hline 13 & $\begin{array}{r}\text { D } \\
\text { ND }\end{array}$ & $\begin{array}{l}2 \\
1\end{array}$ & $\begin{array}{l}0 \\
8\end{array}$ & $\begin{array}{l}0 \\
5\end{array}$ & $\begin{array}{l}3 \\
6\end{array}$ & $\begin{array}{l}6 \\
1\end{array}$ & $\begin{array}{l}0 \\
3\end{array}$ & $\begin{array}{l}11 \\
24\end{array}$ \\
\hline 14 & $\begin{array}{r}\text { D } \\
\text { ND }\end{array}$ & $\begin{array}{l}0 \\
7\end{array}$ & $\begin{array}{l}0 \\
8\end{array}$ & $\begin{array}{l}0 \\
2\end{array}$ & $\begin{array}{l}3 \\
8\end{array}$ & $\begin{array}{l}7 \\
4\end{array}$ & $\begin{array}{l}0 \\
1\end{array}$ & $\begin{array}{l}10 \\
30\end{array}$ \\
\hline 15 & $\begin{array}{r}\text { D } \\
\text { ND }\end{array}$ & $\begin{array}{l}0 \\
7\end{array}$ & $\begin{array}{l}3 \\
8\end{array}$ & $\begin{array}{l}6 \\
7\end{array}$ & $\begin{array}{l}2 \\
7\end{array}$ & $\begin{array}{l}4 \\
8\end{array}$ & $\begin{array}{l}3 \\
8\end{array}$ & $\begin{array}{l}18 \\
45\end{array}$ \\
\hline & $\mathbf{P}$ & $<0.005$ & $<0.01$ & 0.005 & 0.005 & $>0.025$ & $<0.01$ & \\
\hline
\end{tabular}

ND = Unoccluded, $\mathrm{D}=$ Occluded.

response is defined as one that is to the same side of the subject as the signal; a contralateral response is to the side opposite. Referring to the Figure, it is clear that when the stimulus is at loudspeaker 1 (stimulus A), responses in categories I, II, and III are ipsilateral and those in IV, V, and VI are contralateral. All these categories are errors apart from A I. The ipsilateral and contralateral responses for all stimulus positions are as follows:
Stimulus

(
A
B
C E
D
I, II, III IV, V, VI
IV, V, VI
I, II, III

Response

Contralateral 
The scores obtained by each subject have been divided into ipsilateral and contralateral for both the $\mathrm{D}$ and ND conditions; these are shown in Table 2. It is clear from this table that without eardefenders (ND) contralateral responses were few in number. With ear-defenders every subject except one showed an increase in contralateral responses. The effect of ear-defenders on the occurrence of contralateral responses was significant (Wilcoxon test $\mathbf{N}=14, T=0, P<0.005)$. As would be expected, the ipsilateral responses were correspondingly fewer in the $\mathrm{D}$ condition. Theimplications of this finding are discussed later.

TABLE 2

IPSILATERAL AND CONTRALATERAL RESPONSES FOR ND AND D, 15 SUBJECTS

\begin{tabular}{c|c|c|c|c}
\hline \multirow{3}{*}{ Subject } & \multicolumn{2}{|c|}{$N D$} & \multicolumn{2}{c}{ D } \\
\cline { 2 - 5 } & Ipsi & Contra & Ipsi & Contra \\
\hline 1 & 48 & 0 & 43 & 3 \\
2 & 48 & 0 & 33 & 7 \\
3 & 48 & 0 & 44 & 4 \\
4 & 46 & 1 & 38 & 10 \\
5 & 48 & 0 & 41 & 2 \\
& & & & \\
6 & 47 & 1 & 41 & 7 \\
7 & 47 & 1 & 30 & 16 \\
8 & 48 & 0 & 39 & 4 \\
9 & 47 & 0 & 32 & 6 \\
10 & 45 & 1 & 43 & 1 \\
& & & & \\
11 & 48 & 0 & 41 & 2 \\
12 & 47 & 1 & 44 & 3 \\
13 & 46 & 2 & 32 & 16 \\
14 & 42 & 6 & 24 & 23 \\
15 & 47 & 0 & 34 & 9 \\
& & & & \\
\hline
\end{tabular}

Front and rear errors The system for the analysis of the front-rear distribution of the ipsilateral errors is given below:

\begin{tabular}{cll} 
Stimulus & \multicolumn{2}{c}{ Response } \\
& Front & Rear \\
A & & II, III \\
B & I & III \\
C & I, II & \\
D & V, VI & \\
E & VI & IV \\
F & & IV,,
\end{tabular}

The scores for each subject are shown in Table 3; the four score columns give respectively the total number of frontward errors for ND, rearward for $N D$, frontward for $D$, and rearward for $D$. The Wilcoxon test showed no significant difference between the frontward errors, D, compared with ND. Neither was there a significant difference between the two rearward columns.
TABLE 3

Front and Rear ERrors (IPSILATERAL) FOR CONDITIONS ND AND D, 15 SUBJECTS

\begin{tabular}{c|r|r|r|r}
\hline \multirow{2}{*}{ Subject } & \multicolumn{2}{|c|}{$N D$} & \multicolumn{2}{c}{$D$} \\
\cline { 2 - 5 } & Front & Rear & Front & Rear \\
\hline 1 & 0 & 0 & 3 & 7 \\
2 & 0 & 9 & 3 & 2 \\
3 & 3 & 3 & 4 & 6 \\
4 & 6 & 19 & 5 & 19 \\
5 & 0 & 0 & 2 & 7 \\
& & & & \\
6 & 4 & 9 & 14 & 17 \\
7 & 7 & 6 & 3 & 7 \\
8 & 5 & 21 & 7 & 11 \\
9 & 6 & 9 & 5 & 6 \\
10 & 0 & 0 & 2 & 7 \\
& & & & \\
11 & 1 & 0 & 0 & 2 \\
12 & 11 & 1 & 8 & 1 \\
13 & 6 & 16 & 5 & 16 \\
14 & 6 & 6 & 5 & 9 \\
15 & 1 & 1 & 7 & 9 \\
& & & & \\
\hline
\end{tabular}

However, when the front-rear distribution was compared within conditions, it was found that the number of rearward errors in the $D$ condition significantly exceeded the forward ones (Wilcoxon test, $\mathrm{N}=15, \mathrm{~T}=14.5, \mathrm{P}<0.005)$. These results are referred to in the discussion that follows.

\section{Sensation level}

The effect of sensation level was examined by comparing the correct responses at two sensation levels $(10$ and $30 \mathrm{~dB})$ first without and then with defenders. The scores for all 15 subjects are given in Table 4.

In the ND condition the scores at $30 \mathrm{~dB}$ SL were significantly higher than at $10 \mathrm{~dB}$ SL $(\mathrm{N}=13$, $T=13.5, P=0.01)$. In the $D$ condition, although they were in the same overall direction, the differences just failed to reach the level of significance. A further comparison was made between the 30 $\mathrm{dB}$ SL $\mathrm{D}$ and the $10 \mathrm{~dB}$ SL ND. There were significantly more correct responses at the lower sensation level in the ND condition $(\mathrm{N}=14, \mathrm{~T}=12$, $P<0.005)$.

\section{Discussion}

It is evident that, in this experiment, the effect of binaural occlusion by ear-defenders considerably reduced the accuracy of direction perception of a $1 \mathrm{KHz}$ pure tone. The proportion of correct responses fell from $76 \%$ to $50 \%$ for the group as a whole.

The major contribution to this drop in ability was the marked rise in left/right errors (contralateral 
TABLE 4

Correct Scores for Two Sensation Levels, CONDITIONS ND AND D FOR 15 MEN

\begin{tabular}{c|r|r|r|r}
\hline \multirow{3}{*}{ Subject } & \multicolumn{2}{|c|}{$N D$} & \multicolumn{2}{c}{$D$} \\
\cline { 2 - 5 } & $10 d B S L$ & $30 d B S L$ & $10 d B S L$ & $30 d B S L$ \\
\hline 1 & 9 & 12 & 5 & 10 \\
2 & 11 & 11 & 8 & 7 \\
3 & 9 & 12 & 5 & 8 \\
4 & 5 & 6 & 5 & 2 \\
5 & 11 & 12 & 6 & 8 \\
& & & & \\
6 & 7 & 9 & 3 & 1 \\
7 & 4 & 10 & 7 & 6 \\
8 & 5 & 4 & 4 & 5 \\
9 & 8 & 6 & 6 & 3 \\
10 & 12 & 12 & 7 & 10 \\
& & & & \\
11 & 12 & 11 & 8 & 11 \\
12 & 8 & 10 & 4 & 10 \\
13 & 6 & 7 & 2 & 3 \\
14 & 5 & 9 & 3 & 2 \\
15 & 10 & 12 & 2 & 6 \\
& & & & \\
\hline
\end{tabular}

scores) when both ears were occluded. Without ear-defenders the group as a whole made $13 \mathrm{left} /$ right errors; with defenders that number rose to 113 , every subject except one showing the increase. It is the rarity of this type of error under open-ear conditions that makes the increase so important: this is obviously not an error that people would expect to make.

Ferree and Collins (1911), Bauer, Matuzsa, Blackmer, and Glucksberg (1966), and Butler and Naunton (1967) tested monaural localization by occluding one ear of their subjects; all of these authors write of shifts towards the side of the unoccluded ear. Such shifts are contralateral errors and whether our observations are a different aspect of some basic underlying phenomenon remains to be seen.

In contrast with the left/right errors there were not significantly more forward errors when the ear-defenders were being used; neither were there significantly more rearward errors. But the eardefenders did appear to influence the numbers of the two types of error, there being significantly more rearward than forward errors when the defenders were being worn. From the excess of rearward errors it seems almost as if the subjects made the 'safest' guess, a phenomenon which has been observed before (Stevens and Newman, 1936).

It was clear that sensation level was a material factor in the unoccluded condition, an observation that is in agreement with the findings of Butler and Naunton (1967). In our experiment the influence of sensation level may also have been present with the ear-defenders, and it raises the question whether the overall difference observed between the two conditions was in fact due to differences in the range of sensation level rather than to the defenders themselves. We have compared the low sensation level in the open ear condition with the high sensation level in the occluded condition. The difference in the number of errors in the occluded condition is still significantly higher than in the unoccluded condition, showing that even with a high, and therefore favourable, signal level the effect of occlusion is still very apparent.

Because in both D and ND conditions we used sensation level as the measure of signal level, each subject was able to hear every signal with or without defenders; furthermore, we would not expect individual hearing level to influence the experimental results. However, there remains the possibility that it could have an effect. To examine this the correlation coefficient has been calculated between hearing level for pure tones (measured with earphones using a self-recording audiometer) at each of six test frequencies in each ear and the total incorrect score for each man in both open and occluded ears. The results, given in Table 5, show that the highest associations between direction perception for $1 \mathrm{KHz}$ in the open ear condition and right ear hearing level occur at 2 to $6 \mathrm{KHz}$ but that the relationship is slight between the two variables when the ears are occluded. This indicates that hearing level, as measured with an audiometer, was certainly not a factor of importance in our study when subjects were wearing ear-defenders.

\section{TABLE 5}

Correlation Coefficients (Spearman) Between

Hearing Level for Pure Tones in Each Ear at Six Frequencies and Direction Perception IN ND AND D CONDITION (15 SUbJeCTS)

\begin{tabular}{c|c|l|l|l}
\hline \multirow{2}{*}{$K H z$} & \multicolumn{2}{|c|}{$N D$} & \multicolumn{2}{c}{$D$} \\
\cline { 2 - 5 } & Left & Right & \multicolumn{1}{|c}{ Left } & \multicolumn{1}{|c}{ Right } \\
\hline 0.5 & 0.054 & 0.433 & 0.199 & 0.090 \\
1 & 0.044 & 0.180 & 0.254 & 0.083 \\
2 & 0.303 & $0.459^{1}$ & 0.053 & 0.121 \\
3 & 0.360 & $0.529^{1}$ & 0.136 & 0.388 \\
4 & 0.409 & 0.451 & 0.356 & 0.418 \\
6 & 0.343 & $0.538^{1}$ & 0.318 & 0.410 \\
\hline
\end{tabular}

$1 \mathrm{P}<0.05$

One other factor which must be mentioned is that of adaptation. The work of Bauer and his colleagues (1966) showed that subjects were able to adapt to alterations in direction perception while one ear was constantly occluded. The adaptation usually 
took about three days. It is possible that with continued use the effect of ear-defenders on direction perception would be less noticeable. In a factory situation ear-defenders are not used constantly and it is difficult to know, therefore, whether adaptation would in fact take place.

Our results give substance to the complaints made by workers about ear-defenders; indeed the perturbing effect of ear-defenders on direction perception is what we would expect intuitively. We cannot at this stage say whether, had head restraint been used, the effect of ear-defenders would have been greater.

From the theoretical point of view, the result is not easy to explain. Broadly speaking, there are two schools of thought regarding the mechanism of direction perception and our findings support neither conclusively. There are those who emphasize the importance of interaural differences in phase, time, and intensity of signals. There are others who point out that direction perception is not disturbed by monaural occlusion. The latter writers stress the role of the pinna whose shape, it is argued, allows discrimination of signals from different directions especially in conjunction with small movements of the head. Placing ear-defenders over the ears of our subjects effectively deprived them of such a function of their pinnae; certainly their precision of judgement suffered but it was not wholly impaired.

The 'two-ear' school has studied the relative importance of interaural differences and, according to Nordlund (1962), the interaural phase difference at $1 \mathrm{KHz}$ is the most important factor in direction perception. It is difficult to see how a symmetrical ear-defender could interfere with interaural phase differences. Neither can we understand how eardefenders would interfere with interaural time differences.
Obviously further research is required: other frequencies and other types of hearing protection must be investigated. However, we believe, on the basis of the present evidence, that ear-defenders need to be viewed with suspicion from the point of view of safety in industry. When an individual is uncertain whether a sound is from the front or the rear, he generally makes the assumption, presumably for survival's sake, that it is coming from behind, unless, of course, he can see that the source is in front of him. Left/right errors are an uncommon experience in normal direction perception: eardefenders, by increasing their incidence, could increase the likelihood of incorrect action and so of accidents.

\section{References}

Bauer, R. W., Matuzsa, J. L., Blackmer, R. F, and Glucksberg, S. (1966). Noise localization after unilateral attenuation. $J$. acoust. Soc. Amer., 40, 441-444.

Butler, R. A., and Naunton, R. F. (1967). The effect of stimulus sensation level on the directional hearing of unilaterally deafened persons. J. audit. Res., 7, 15-23.

Ferree, C. E., and Collins, R. (1911). An experimental demonstration of the binaural ratio as a factor in auditory localization. Amer. J. Psychol., 22, 250-297.

Fisher, H. G., and Freedman, S. J. (1968). Localization of sound during simulated unilateral conductive hearing loss. Acta otolaryng. (Stockh.), 66, 213-220.

Howard, I. P., and Templeton, W. B. (1966). Human Spatial Orientation. John Wiley, London.

Jongkees, L. B. W., and van der Veer, R. A. (1957). Directional hearing capacity in hearing disorders. Acta oto-laryng. (Stockh.), 48, 465-474.

Mills, A. W. (1958). On the minimum audible angle. J. acoust. Soc. Amer., 30, 237-246.

Nordlund, B. (1962). Angular localization. Acta oto-laryng. (Stockh.), $55,405-424$.

Stevens, S. S., and Newman, E. B. (1936). The localization of actual sources of sound. Amer. J. Psychol., 48, 297-306.

Wallach, H. (1940). The role of head movements and vestibular and visual cues in sound localization. J. exp. Psychol., 27, 339-368.

Received for publication October 27, 1969. 